\title{
Motivation crowding in real consumption decisions: \\ Who is messing with my groceries?
}

Grischa Perino*, Luca A. Panzone†, and Timothy Swanson¥1

Forthcoming in Economic Inquiry

\begin{abstract}
We present evidence of crowding out of intrinsic motivation in real purchasing decisions from a field experiment in a large supermarket chain. We compare three instruments, a label, a subsidy and a neutral price change, in their ability to induce consumers to switch from dirty to clean products. Interestingly a subsidy framed as an intervention is less effective than either a label or a neutrally framed price change. We argue that this provides a new explanation for crowding behaviour: consumers are resistant to having the line of demarcation between public and private decision making moved - in either direction.
\end{abstract}

\section{Keywords: Motivation Crowding; Field experiment; Consumer Behaviour; Intervention. JEL codes: C93, Q18, Q54, Q58, H23, H41}

* Corresponding author: School of Economics, CSERGE and CBESS, University of East Anglia, Norwich Research Park, Norwich NR4 7TJ, United Kingdom, g.perino@uea.ac.uk, Tel: +44 160359 1090, Fax: +441603456259

$\dagger$ University of Manchester, 188 Waterloo Place, Oxford Road, Manchester M13 9PL, United Kingdom, luca.panzone@manchester.ac.uk

‡ Graduate Institute of International and Development Studies, Voie-Creuse 16, CP 136, 1211 Genève 21, Switzerland, tim.swanson@graduateinstitute.ch

\footnotetext{
${ }^{1}$ We are grateful to Denise Leung (University College London), who did excellent work in the data collection process, and the supermarket chain Sainsbury's for permission to run the experiment in their stores. We are indebted to the FP7 project EUPOPP (www.eupopp.net) for providing the funding required for the field experiment. We gratefully acknowledge comments from the editor, two anonymous referees, participants of EU-POPP project meetings, seminar participants at the universities of Beijing, East Anglia, Heidelberg, Lüneburg and Manchester and participants at the 2011 AERE and EAERE annual conferences.
} 


\section{Introduction}

Intrinsic motivation, the desire to perform a task or contribute to a public good for its own sake rather than out of narrow material interests, has been found important in the private provision of public goods, e.g. in the form of charitable giving, volunteering and many other contexts. ${ }^{2}$ There is also substantial evidence that intrinsic motivation interacts with regulatory interventions in the form of monetary rewards, fines or minimum contributions, either positively (crowding-in) or more commonly negatively (crowding-out). ${ }^{3}$ Crowding effects have been observed either when moving from a non-market to a market situation ${ }^{4}$, or in principal-agent settings ${ }^{5}$. The latter does not involve provision of a public good but of effort that benefits the principal at a cost to the agent. Whether motivation crowding exists within purely market contexts has been controversial (Fehr and Falk 2002, Ariely et al. 2009) but has remained an untested hypothesis. However, its presence can interfere with the effectiveness of regulatory interventions intended to stimulate pro-social behaviour, making this issue relevant for both researchers and policymakers.

We provide the first experimental evidence of motivation crowding in real purchasing decisions. ${ }^{6}$ Using food purchases of more than five hundred customers at a leading UK supermarket, we compare the impact of different regulatory interventions on grocery choices. Climate change mitigation, in the form of a product's carbon footprint, serves as the public good. For the intrinsic motivation to privately contribute to its provision to be behaviourally relevant (or 'activated') in a particular context requires information about the public good dimension of available choices. In this experiment we choose the impure public good context of grocery shopping (cola, milk, meat and butter/margarine) with products differing in their lifecycle carbon footprints.

Crowding out occurs if an explicit regulatory intervention reduces the willingness of an individual to buy a 'clean' product compared to an equivalent change in incentives without an

\footnotetext{
${ }^{2}$ See e.g. Andreoni (1989), Frey (1997), Meier and Stutzer (2008) and Corgnet (2012).

${ }^{3}$ For surveys of the literature on motivation crowding see Bowles (2008) and Frey and Jegen (2001).

4 See e.g. Frey and Oberholzer-Gee (1997), Gneezy and Rustichini (2000a,b), Heyman and Ariely (2004), Meier (2007),

Mellström and Johannesson (2008), Charness and Gneezy (2009) and Ariely et al. (2009) .

5 See e.g. Frey (1993), Fehr and Schmidt (2000) and Falk and Kosfeld (2006) and Arce (2007) for an evolutionary explanation.

${ }^{6}$ Landry et al. (2011) tested for crowding out in naturally occurring labour markets and do not find crowding out.
} 
explicitly interventionist character. ${ }^{7}$ For marketed goods prices change as a matter of routine and a small change in price would not give rise to crowding effects in the absence of information on how it came about. Crowding out, however, may occur when a government deliberately alters the incentive system of consumers. Explicit interventions are a key component of most crowding theories.

We analyse how consumers respond to such government interventions within the marketplace. Our experimental treatments focus on the context of otherwise equivalent changes in prices. The context for changes in prices is important for two reasons. The first is the information transmitted on the intervention, which might trigger a strategic response by consumers (Bénabou and Tirole, 2003; Sliwka, 2007; Ellingsen and Johannesson, 2008). The second reason is a pure "framing effect". Knowing that a change in price is caused by a deliberate intervention might trigger psychological mechanisms such as over-justification (tangible extrinsic motivation crowds out intangible intrinsic motivation) ${ }^{8}$, or a reduction in perceived self-determination (deliberate interference by a third party reduces an individuals' autonomy which in turn reduces its intrinsic motivation, see Deci and Ryan, 1985).

We are not the first to investigate how context affects responses to changes in prices or choice sets. Kahneman et al. (1986) use survey data on the perception of price changes and do not refer to intrinsic motivation. Eckel and Grossman (2003) compare two functionally equivalent subsidy schemes for charitable giving, both are explicit interventions. Kallbekken et al. (2011) provide experimental evidence that acceptance of a Pigouvian tax is reduced when it is called a 'tax' rather than a 'fee'. Falk and Kosfeld (2006) and Schnedler and Vadovic (2011) investigate crowding effects in a principal-agent model where the principal can restrict the agent's choice set. The closest study to ours is the classroom experiment in Goeschl and Perino (2012) comparing price and quantity-based instruments with neutrally framed controls. The main differences to the current paper are that they used direct payments as the private and purchases of EU ETS emission allowances as the public good

\footnotetext{
${ }^{7}$ As we study only one context (grocery shopping) we are unable to distinguish between a reduction in the underlying intrinsic motivation to mitigate climate change and a reduction in the extent to which this becomes activated in a particular context. Previous contributions on didn't require this distinction as they studied direct contributions to the public good (donations, fundraising effort, purchases of emission allowances).

${ }^{8}$ see Bem (1967).
} 
while we use real grocery products bought by normal customers in a supermarket. Moreover, they compare a tax with a neutrally framed price change and an emission standard enforced by a fine while we compare a subsidy with a neutrally framed price change and a labelling treatment. However, both studies find clear evidence of crowding out of intrinsic motivation to reduce greenhouse gas (GHG) emissions as a result of an explicit monetary incentive compared to a non-interventionist price change.

Our fundamental results can be summarised as follows: First, we find that information provided via a label activates intrinsic motivation to contribute to a public good in the context of grocery choices. Labelling induces a significant shift towards cleaner consumption decisions. On the other hand, we find that an explicit subsidy which combines information on relative GHG emissions with a monetary incentive results in a smaller change in behaviour than labelling. This is an example of consumption-based crowding-out: the impact of norm activation and the response to a relative price change are sub-additive. More striking is the fact that the subsidy is having less of an impact than a neutrally framed price change A phenomenon we label over-crowding. This indicates that consumers object to be regulated in traditionally private realms, such as grocery shopping

The context of the experiment, the capacity of instruments to activate intrinsic motivation of consumers to contribute to climate change mitigation, is highly relevant for policy making. Food production significantly contributes to GHG emissions and diet choices are an important determinant of a household's carbon footprint. However, relatively little work has been done on how to induce consumers to switch to less GHG intensive diets. We investigate the ability of instruments to complement rather than substitute intrinsic motivation in public goods provision.

The remainder of the paper is structured as follows. Section 2 describes the experiment. Section 3 derives testable hypotheses on the effect of different regulatory interventions. Section 4 presents results. The last section discusses the policy implications of our findings and concludes.

\section{The Experimental Setup}


The experiment was conducted in seven Sainsbury's supermarket ${ }^{9}$ stores in the Greater London area $^{10}$ in February and March 2010.11 The experiment had two parts. The computer-based first part took place in the entrance area of a store and participants made purchasing decisions with carbon footprint information and prices controlled by randomly assigned treatments. This part mimiced online grocery shopping, a commonplace phenomenon in the UK.12 The second part of the experiment was the actual shopping trip in the main part of the supermarket. Decisions made in the first part of the experiment were enforced by making payment conditional on matching purchases being made in the second part. .

A table with laptop computers was placed in the entrance area of the stores and a sign announced the opportunity to earn a $£ 5$ voucher for participation in a university-sponsored grocery shopping study. Anyone interested in participating was given a leaflet stating the eligibility criteria and the payment procedure (see Appendix B). The purpose of the experiment was described as "studying how people make REAL LIFE grocery shopping decisions". No other information on the purpose of the experiment was provided. In particular, environmental motivations were not mentioned at any point during the recruitment phase. Interested shoppers were only turned down if they a) did not intend to buy any of the product categories listed (cola in cans, butter, beef or milk), b) did not speak or read English, c) were not at least 21 years of age or, d) had participated in the experiment previously ${ }^{13}$. While our sample is not a random sample, participants span a diverse set of socio-economic backgrounds. The age range was 21-80 years of age (mean: 37 ) and included a wide range of incomes, educational backgrounds, and political, ethnic and religious groups.

\footnotetext{
${ }^{9}$ Sainsbury's accounts has a market share of $27 \%$ in the study area (http://www.j-sainsbury.co.uk/index.asp?pageid=451), and $16 \%$ in the UK. It has a well developed internet shopping facility that reaches $88 \%$ of the UK population, with over $£ 500$ millions worth of sales in 2009 (http://www.j-sainsbury.co.uk/files/reports/ar2009 report.pdf, page 5. This value only includes food and grocery products, as the non-food area has only been launched in 2010).

10The stores were chosen by moving along the circumference of a radial approximately 7 miles from the center of London, and provide a geographically dispersed sample from the London metropolitan area. Stores were located in Walthamstow, New Barnet, Edgware, Chiswick, Merton, and Lewisham. Each was surveyed for 8 hours a day for 2 days, with the exception of Edgware, where the experiment lasted 4 days.

11 In the classification of Harrison and List (2004) the experiment is between a framed and a natural field experiment. It involves a non-standard subject pool (supermarket customers), field context in commodity (grocery products), task (purchasing these products) and information (on prices, availability and characteristics of products) and is conducted in an environment where subjects usually undertake this task (in the supermarket during the actual shopping trip). However, subjects were aware that they were participating in an experiment.

${ }^{12}$ Online grocery shopping is prevalent in the UK with over a third of adults shopping for food online in 2009, and a significant proportion of UK consumers do most of their grocery shopping in this manner (Mintel, 2009).

13 The same experimenter was present during the entire experiment which together with the frequent change of location minimised the risk of the same person participating more than once.
} 
In each of four categories (cola drinks, butter/margarine spreads, fresh meat products and milk) products with the largest market shares available in the stores were included in the experiment. The prices, sizes and photos of the products were identical to those available in the store, and displayed in a manner as close as possible to the store's own online portal. The objective was to create a real but controlled and incentive compatible choice environment as close as possible to consumers' normal shopping experience.

The purchasing decision was a real one. Incentive compatibility was achieved by conferring a $£ 5$ voucher only upon those who in the second part purchased the goods chosen in the first part ${ }^{14}$ (see the "Consumer Contract" attached in Appendix B). Participants were informed about this procedure beforehand. The compliance rate was $96 \%$.

In the computerised part participants could select one or more of the four product categories set out in Table 1. In each of these categories they were presented with a range of varieties/brands. These alternatives provided the participant with a range of options catering to different tastes, but also with very different public good components. The cola category for example contained six different varieties (differentiated by brand and nutritional characteristics). The public good dimension was added by making each variety available in two different packagings: six-pack of aluminium cans and a single PET bottle, both containing the same total amount of cola. Cola purchased in cans has twice the carbon footprint of cola in a bottle.

Based on photographs of all of the products listed in Table 1 and their current in-store prices (see Appendix B) participants made an initial choice in each product category selected. This first choice constitutes their baseline which was identical for all participants.

After that, all participants could obtain more information on environmental and nutritional matters. These explained in general terms the information that is provided on food labels - the

\footnotetext{
${ }^{14}$ Compensation was paid only if participants completed the computer-based experiment, had their choices recorded on a paper slip, signed off by the experimenter, returned to the experimenter (stationed at the store's exit) with their slip, purchasing receipt and shopping basket at the end of the shopping trip. In the case of the Subsidy and the NeutralPriceChange treatments, participants also received the difference between the price announced in the computer-based part of the experiment and the real (unaltered) in-store prices if they purchased any subsidised option.
} 
meaning of nutritional or of carbon footprint information - but did not give any product specific details. The information provided was the same across all treatments. ${ }^{15}$

Table 1: Products offered in the experiment

\begin{tabular}{|c|c|c|c|c|c|c|}
\hline $\begin{array}{l}\text { Product } \\
\text { Categories }\end{array}$ & Quantity & Options & $\begin{array}{c}\text { Carbon } \\
\text { Footprint (in } \\
\mathrm{CO}_{2} \mathrm{e} \text { ) }\end{array}$ & $\begin{array}{l}\text { Original } \\
\text { Price }\end{array}$ & $\begin{array}{l}\text { Subsidy/Price } \\
\text { Reduction }\end{array}$ & Brands/Varieties \\
\hline \multirow{2}{*}{ Cola } & \multirow{2}{*}{21} & $\begin{array}{l}\text { Cans (six } \\
\text { pack) }\end{array}$ & $1,020 \mathrm{~g}$ & $\begin{array}{c}£ 2.63- \\
£ 2.69\end{array}$ & & \multirow{2}{*}{$\begin{array}{l}\text { Coca Cola, Pepsi Cola, } \\
\text { Diet Coke, Diet Pepsi, } \\
\text { Coke Zero, Pepsi Max }\end{array}$} \\
\hline & & PET bottle & $500 \mathrm{~g}$ & $\begin{array}{l}£ 1.56- \\
£ 1.59\end{array}$ & $5 p$ & \\
\hline \multirow{3}{*}{ Milk } & \multirow{3}{*}{2 pint } & Whole & $1,800 \mathrm{~g}$ & $£ 0.86$ & & \multirow{3}{*}{$\begin{array}{l}\text { Sainsbury's own } \\
\text { brand fresh milk }\end{array}$} \\
\hline & & $\begin{array}{c}\text { Semi- } \\
\text { skimmed }\end{array}$ & $1,600 \mathrm{~g}$ & $£ 0.86$ & $3 p$ & \\
\hline & & Skimmed & $1,400 \mathrm{~g}$ & $£ 0.86$ & $6 p$ & \\
\hline \multirow{2}{*}{ Meat } & \multirow{2}{*}{$\begin{array}{l}\text { Various } \\
\text { weights }\end{array}$} & Beef & $\begin{array}{c}16,000 \mathrm{~g} / \mathrm{kg} \\
\text { of beef }\end{array}$ & $\begin{array}{c}£ 4.40- \\
£ 7.93 \\
\text { per } 1 \mathrm{~kg}\end{array}$ & & $\begin{array}{l}\text { minced meat, } \\
\text { casserole steak, } \\
\text { braising steak }\end{array}$ \\
\hline & & Chicken & $\begin{array}{l}5,000 \mathrm{~g} / \mathrm{kg} \text { of } \\
\text { chicken }\end{array}$ & $\begin{array}{c}£ 3.39- \\
£ 9.16 \\
\text { per } 1 \mathrm{~kg}\end{array}$ & $21 \mathrm{p} / \mathrm{kg}$ & $\begin{array}{l}\text { chicken breast, mini } \\
\text { chicken fillet, } \\
\text { drumsticks }\end{array}$ \\
\hline \multirow[t]{2}{*}{ Spreads } & \multirow[t]{2}{*}{$500 \mathrm{~g}$} & Butter & $11,900 \mathrm{~g}$ & $\begin{array}{l}£ 1.70- \\
£ 2.76\end{array}$ & & $\begin{array}{l}\text { Lurpak, Anchor, } \\
\text { Countrylife, } \\
\text { Kerrygold, } \\
\text { Sainsbury's own } \\
\text { brand }\end{array}$ \\
\hline & & Margarine & $675 \mathrm{~g}$ & $\begin{array}{l}£ 1.00- \\
£ 2.38\end{array}$ & $43 p$ & $\begin{array}{l}\text { Lurpak, Anchor, } \\
\text { Flora, Clover, } \\
\text { Sainsbury's own } \\
\text { brand }\end{array}$ \\
\hline
\end{tabular}

Then participants were randomly assigned to one of three treatments. ${ }^{16}$ There are two instrument (Labelling, Subsidy) and one neutrally framed control (NeutralPriceChange) treatment. This allowed consumers to revise their initial choices based on the new information/incentives

\footnotetext{
15 The dummy variables Envinfo and Nutrinfo recording whether a participant has opted to see the corresponding type of information have been used as controls in the regressions reported in section 4 but coefficients are not reported as they are not significant the $10 \%$-level.

16 Participants who selected more than one product category completed the first choices for all categories before moving to the second choices and were subject to the same treatment throughout.
} 
imposed by the treatment. Having a baseline and a treatment choice for each participant is essential as it allows isolating the impact of treatments on behaviour from any unobserved differences in treatment groups. Treatments can then be compared using a difference-in-difference analysis focusing on differences in behavioural change across treatments. The order (baseline - treatment) is driven by the desire to understand the effect of introducing (rather than removing) a regulatory intervention. However, previous contributions (Frohlich and Oppenheimer, 2003; Meier, 2007; Goeschl and Perino, 2012) showed that motivation crowding can be short term persistent and hence we would expect similar results if the order were reversed.

The Labelling treatment was intended to be as simple and non-leading as possible and presented consumers with two sets of information: a nutritional and a carbon footprint label. The former was a replication of the fine print that appears on these goods giving information on calories, protein, carbohydrate, fat and salt content. The nutritional information was intended to reduce the risk of participants guessing the purpose of the experiment and then trying to please the experimenter (experimenter demand effect). Since the information was the same as on the packages, this was expected to have only a small effect on choices as consumer caring about these characteristics would be already aware of them. Moreover, variations in nutritional characteristics and carbon footprints were perfectly orthogonal for one product category (Cola) which allows to test for confounding effects. The carbon footprint label followed the design provided by the Carbon Trust UK. It is used by another major supermarket chain in the UK for own brand products but not for the products in this experiment. The label has the form of a stylized footprint and shows the amount of carbon dioxide equivalent GHG emissions caused over the life-cycle of the product in grams. ${ }^{17}$

The Subsidy treatment stated that the government intervened by subsidising products with lower carbon footprints. The instructions (here for cola) read "There has been a price change. Products in plastic bottles have a $5 p$ discount due to a GOVERNMENT SUBSIDY received on account of its low carbon footprint". This is to be contrasted with the non-interventionist NeutralPriceChange treatment that was identical to the Subsidy treatment with the exception of the motivation given for the price

17 A graphical representation of the label can be found in the experimental instructions provided in the appendix. We wish to thank the Carbon Trust for their cooperation and assistance. 
change (market conditions rather than government intervention). The instruction for the NeutralPriceChange treatment read (again for cola) "There has been a price change. Products in plastic bottles have a $5 p$ discount because of a change in the price of materials".

Note that there are two differences between the Subsidy treatment and its control: a) the explicit interventionist character and b) information about the relative ranking of products with respect to their carbon footprint. ${ }^{18}$ The control treatment has neither while the Subsidy treatment has both (intervention and information).

Both before and after the price reduction the cheapest product was always a clean one (with the exception of milk where all option cost the same in the baseline) and the most expensive option was the same before and after the price change. A participant regarding clean and dirty options as perfect substitutes and without intrinsic motivation should not change her mind between baseline and treatment choice in any of the treatments.

Following the experiment, socio-demographic details on the respondents were collected. A total of 570 shoppers completed the task and complied with all terms and conditions of the experiment, and are included in the sample. The number of participants and hence independent observations per treatment were: 237 for Subsidy, 248 for NeutralPriceChange and 85 for Labelling. 333 participants chose only one product category, 154 made choices in two, 66 in three, and only 17 made purchases from all four categories. This resulted in 907 pairs of purchasing decisions.

\section{Switching Behaviour with Intrinsic Motivation}

In this section we derive testable hypotheses of the switching behaviour of intrinsically motivated consumers who use private consumption decisions to determine their contribution towards public goods. To obtain a clear benchmark, the activation of intrinsic motivation is assumed to be

\footnotetext{
18 In contrast to the Labelling treatment the subsidy explicitly provided only information on the relative ranking of products (clean vs. dirty) as would be the case in a real world subsidy. However, the size of the subsidy was proportional to the difference in carbon footprints within each product category.
} 
independent of the regulatory instrument (Heyes and Kapur, 2011). Hence hypotheses are based on the assumption that there is no motivation crowding.

Goods with lower carbon emissions (i.e. the "carbon footprint" of the product concerned) are referred to as the "clean" options, goods with higher carbon footprints as "dirty". In order for intrinsic motivation to be behaviourally relevant, participants require information allowing them rank private goods with respect to the levels of the public good provided with each. The carbon footprint does exactly this. ${ }^{19}$

As participants are choosing between everyday products that were on their shopping list for that day, it seems reasonable to assume that they were familiar with them. We also assume that providing information on either absolute or relative carbon footprints does not decrease participants' intrinsic motivation to buy clean products. This holds unless the distance between rather than the ranking of products matters and participants initially overestimate the advantage of clean products and update them based on the information provided in treatments. We will consider this when discussing the results. Most likely consumers were not aware of products' (relative) carbon footprints at the start of the experiment since for the products considered carbon footprints were neither in use in the UK nor widely publicised. ${ }^{20}$ For uninformed participants the information provided in the Labelling and Subsidy treatments is essential for intrinsic motivation to be behaviourally relevant.Carbon footprints can induce participants who are intrinsically motivated to mitigate climate change (and who initially bought a dirty product) to switch to a clean one, either because they, for the first time, have the information required to discriminate between clean and dirty products or because pre-existing information has been updated or reinforced. Since the information provided by the label is the only

\footnotetext{
${ }^{19}$ Note that for the carbon footprint of a product to have an impact on the consumption choice of a consumer, she needs to care not only about the environmental public good affected (mitigation of climate change) but also has to have at least some form of intrinsic motivation to contribute to this cause. Intrinsic motivation is a necessary condition since the relevant population of the climate mitigation game is in the order of billions and hence close enough to infinity to drive the Nash contribution down to zero (Andreoni, 1988).

${ }^{20}$ Although the carbon footprints for milk were taken from Tesco (another major supermarket in the UK) they only used footprint labels (similar to those in this study) on the following four product categories: orange juice, potatoes, light bulbs and laundry detergents. No carbon footprint labels were in use at Sainsbury's at the time the study was conducted in any of the product categories included in the experiment.
} 
difference between the two choice situations, intrinsic motivation is the only systematic driver of any switches observed. ${ }^{21}$

\section{Hypothesis 1}

Information on carbon footprints of products will induce some participants to switch from a dirty to a clean product. Participants initially opting for a clean product are not affected.

The NeutralPriceChange treatment tests whether participants respond to small changes in relative prices. For that purpose all clean products received a reduction in prices. The price reductions are given in Table 1. Participants were not made aware that the price change had anything to do with environmental characteristics of the product. Hence, there is no reason why intrinsic motivation should be affected in the NeutralPriceChange treatment.

\section{Hypothesis 2}

A price change will induce some participants to switch from a dirty to a clean product. Participants initially opting for a clean product are not affected.

In the Subsidy treatment participants learned that the government has introduced a subsidy which reduces the price of clean products. Note that the clean products where already cheaper (with the exception of milk where all varieties had the same price) before the price change. Consumers faced a new set of relative prices, were able to rank products in each category according to their carbon footprint (only the cleaner options qualify for the reward) and are aware of the interventionist character of the price change. Except for the latter two aspects which can affect activation of intrinsic motivation but nothing else, the Subsidy treatment is equivalent to the NeutralPriceChange treatment.

\footnotetext{
${ }^{21}$ Note that it does not matter whether consumers perceive the clean product to become better or the dirty product to become worse. All that matters is the change in relative terms.
} 
The monetary reward increased the attractiveness of clean products as does any activation of intrinsic motivation.

Comparing switching behaviour in the Subsidy and the NeutralPriceChange treatments allows isolating the effect of an explicit intervention on intrinsic motivation. Compared to the Labelling treatment, the change in relative prices creates an additional incentive to switch. This gives rise to the following hypotheses:

\section{Hypothesis 3}

(a) The subsidy (for clean products) will induce some participants to switch toward clean products. Participants initially opting for a clean product will be unaffected by the subsidy.

(b) The subsidy will induce more participants to switch from dirty to clean varieties than in either the Labelling or the NeutralPriceChange treatments.

If Hypothesis $3 \mathrm{~b}$ were not confirmed this would indicate crowding out of intrinsic motivation by the explicit price intervention in the Subsidy treatment. Hypotheses 1 - 3a make within-subject comparisons and conjecture a systematic impact of treatments on participants' behaviour compared to the baseline (choice 1). Hypothesis $3 \mathrm{~b}$, central to detecting crowding out, makes between-subject comparisons and predictions about systematic differences between impacts of treatments . All hypotheses make predictions about changes in behaviour induced by treatments and not about initial choices allowing us to abstract from issues like which product is more expensive in absolute terms and focus on changes in relative prices instead.

\section{Results}

This section presents the switching pattern for all treatments and tests the hypotheses formulated in section 3 . We verify whether a carbon label activates intrinsic motivation, if a change in 
relative prices has the expected substitution effect and we test the interaction of price and information in the form of a subsidy. By making comparisons across treatments we identify whether and to what extent there is motivation crowding.

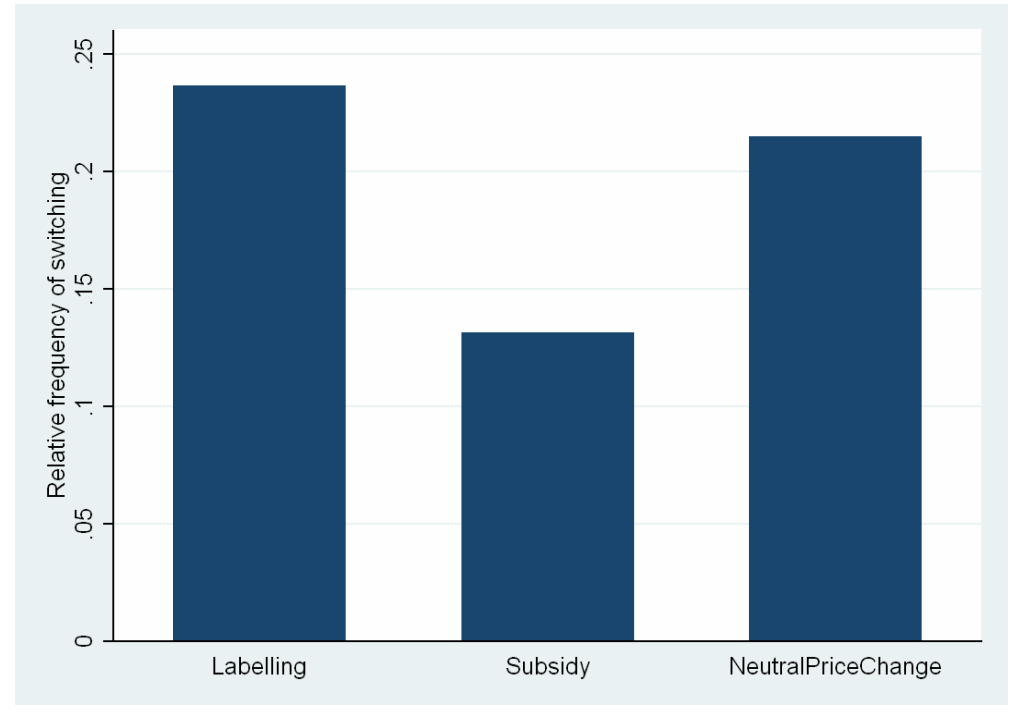

Figure 1: Relative frequencies of switches to clean varieties. All product categories pooled.

Table 2: Relative frequency of switching from a dirty to a clean variety (by product category).

\begin{tabular}{|l|l|l|l|}
\hline & Labelling & Subsidy & NeutralPriceChange \\
\hline Cola & $36.4 \%$ & $27.3 \%$ & $58.7 \%$ \\
\hline Butter/Margarine & $61.5 \%$ & $16.1 \%$ & $20.0 \%$ \\
\hline Meat & $21.1 \%$ & $12.0 \%$ & $14.8 \%$ \\
\hline Milk & $12.0 \%$ & $8.5 \%$ & $13.4 \%$ \\
\hline All products & $23.7 \%$ & $13.2 \%$ & $21.5 \%$ \\
\hline
\end{tabular}

Switching behaviour is presented by treatment in Figure 1 and by treatment and product in Table 2. Labelling and NeutralPriceChange had roughly the same impact, but this varied significantly 
across products which is most likely due to the differences in elasticities of substitutions. For example, the rate of switching between "cola in cans" and "cola in plastic" is higher than between "beef" and "chicken". However, product categories differ in more than one dimension and hence a definitive answer cannot be given.

Most striking is the response to the subsidy. It induces fewer switches than both the NeutralPriceChange and the Labelling treatments in all product categories.

\subsection{Activation of Intrinsic Motivation}

The Labelling treatment provided two sets of information to participants: nutritional information on calories, fat, carbohydrates and salt copied from the products' packages and information about carbon footprints. We first analyse the impact of nutritional information before we turn to carbon footprints.

As expected, the nutritional information had only a small impact on participants' choices. This is most obvious for the cola category where nutritional and environmental variables were perfectly orthogonal. All nutritional aspects were driven by the variety (e.g. Coke vs. Diet Coke) consumed while the carbon footprint was determined by the packaging (bottles vs. cans). All varieties were offered in both forms of packaging. $36.4 \%$ of participants with a dirty baseline choice ( 4 out of 11 ) changed to the cleaner packaging option while only $8.7 \%$ of participants ( 2 out of 23 ) changed cola variety after information on nutrition and carbon footprints was provided. For all product categories pooled together, the only significant difference between nutritional aspects of first and second choices exists for calories and fat (which are correlated with carbon footprints for all product categories except cola) for the subgroup that moved from dirty to clean options. This is despite there being substantial variation (up to two orders of magnitude) between nutritional aspects of varieties within both the clean and dirty options. The irrelevance of nutritional information is intuitive as it is available on product labels and hence participants that strongly care about these attributes already took them into account in their baseline choice. 
Participants that are intrinsically motivated to make a private contribution to climate change mitigation by buying products with a low carbon footprint (compared to substitute goods) may switch from a dirty to a clean product in the Labelling treatment (Hypothesis 1). ${ }^{22}$ To test for such a pattern we compare the choices for milk and the other three products separately. The reason for this split is twofold. Firstly, milk has three different categories (whole/dirty, semi-skimmed/medium and skimmed/clean) while the other products have only two (dirty and clean). ${ }^{23}$ Secondly, participants were pre-selected based on whether they were intending to buy milk, cola in cans, butter or beef (i.e. the dirty variety in each category with the exception of milk). ${ }^{24}$

Out of the 57 participants buying milk, six switched from dirty to clean while no one changed from clean to dirty in the Labelling treatment (see Table A.2). The null hypothesis that the carbon label had no impact on choices is rejected but only at the 10\%-level (Bhapkar ${ }^{25} /$ Stuart-Maxwell tests for marginal homogeneity yield $\mathrm{p}=0.0528 / \mathrm{p}=0.0695$, respectively)

For the other three product categories, $37.2 \%$ (16 out of 43 ) of initial dirty choices but only $10 \%$ (3 out of 30) of initial clean choices were reversed after the label was introduced (see Table A.3). This is significant at the 1\%-level (Bhapkar/McNemar tests for marginal homogeneity, $\mathrm{p}=0.0015 / \mathrm{p}=$ 0.0029). This confirms Hypothesis 1 and hence gives rise to the following first result.

\section{Result 1}

Providing information on the relative environmental performance allows participants to act on or increases pre-existing intrinsic motivation and induces switching towards clean products.

\footnotetext{
22 The carbon label might induce an experimenter demand effect. To reduce confounding information on nutritional characteristics was introduced at the same time as the carbon footprint. Moreover, the tests of Hypothesis 3 suggest that experimenter demand effects are not driving our results.

${ }^{23}$ Here and elsewhere we ignore changes from one dirty (clean) to another dirty (clean) variety, e.g. from Coca Cola in cans to Pepsi Cola in cans. Only switches that have an impact on carbon footprints are considered as switching.

24 The relatively large number of participants (177 across all three treatments) choosing clean products in the first choice (for cola, meat and butter/margarine) is most likely due to participants who entered the experiment because they were willing to purchase one of the above in exchange for the $£ 5$ voucher. While this suggests that some participants might have pursued a strategy that minimised expenditure, this cannot explain any of our results as there is no price change in the Labelling treatment, and the NeutralPriceChange and Subsidy treatments did not move the cheapest item from dirty to clean (or vice versa).

25 The Bhapkar (Bhapkar, 1966) test of marginal homogeneity is a more powerful alternative to the Stuart-Maxwell test (Keele, 1982). They are asymptotically equivalent.
} 


\subsection{Response to a (Pure) Price Change}

We proceed with testing Hypothesis 2, which states that a change in relative prices induces switching towards products that became cheaper. For the milk subsample (175 participants) 21 changed as expected and seven changed in the opposite direction (see Table A.4). This is only marginally significant (Bhapkar/Stuart-Maxwell tests, $p=0.0958 / 0.1019$ ). However, for the other product categories (233 observations, see Table A.5) , there were 45 switches from dirty to clean and 19 from clean to dirty. The null hypothesis that the NeutralPriceChange treatment had no systematic effect is clearly rejected at the $1 \%$ level (Bhapkar/McNemar tests for marginal homogeneity, $p=$ $0.0009 / \mathrm{p}=0.0012$ ). This confirms Hypothesis 2 .

\section{Result 2}

Participants respond to a change in relative prices by substituting towards products for which prices were reduced.

\subsection{Subsidies and Intrinsic (De-) Motivation}

Having established how participants respond to information on relative environmental performance of products and to relative price changes we now investigate the effect of combining the two drivers of behaviour. The Subsidy treatment provides exactly the same monetary incentive as the NeutralPriceChange treatment but combines it with an explicit rationale (framing). The subsidy is paid to increase the attractiveness of products with relatively low carbon footprints. Participants hence learned the relative ranking of products with respect to their carbon footprint. Both effects, price change and intrinsic motivation, work in the same direction and are expected to reinforce each other (Hypothesis 3b). But first we test Hypothesis 3a by checking whether a subsidy has a significant effect on behaviour. 
Surprisingly, the null hypothesis that the subsidy had no systematic impact on choices cannot be rejected for either sample (Bhapkar/Stuart-Maxwell tests for marginal homogeneity, no milk: $p=$ 0.4342/0.4349 and milk: $p=0.4346 / 0.4403)$. For cola, butter/margarine and meat, only $18.4 \%$ (23 out of 125) of dirty initial choices but 19.8\% (18 out of 91) of clean initial choices were reversed (see Tables A.6 and A.7). The subsidy hence has no statistically significant effect on purchasing behaviour. This result is not driven by differences in initial choices between the Labelling, NeutralPriceChange and Subsidy treatments. A Kruskal-Wallis test on equality of populations in choice 1 yields a $p$ - value of 0.5267 (0.4068 for milk subsample).

We investigate this further by testing Hypothesis $3 \mathrm{~b}$, which requires a differences-in-differences analysis and a focus on dirty initial choices. Are people more likely to switch from dirty to clean products in the Subsidy treatment than in the Labelling or NeutralPriceChange treatments? We first perform pair-wise Fisher's exact tests and two-sample tests of equality of proportions using the null hypothesis that the frequency of switching is the same in the Subsidy and the NeutralPriceChange/Labelling treatments. All of them reject equality of frequencies.

Table 3: Test results on equality of switching frequency across treatments.

\begin{tabular}{|l|l|l|}
\hline & Fisher's exact test & Test of proportions \\
\hline Subsidy vs. NeutralPriceChange & 0.011 & 0.009 \\
\hline Subsidy vs. Labelling & 0.021 & 0.017 \\
\hline
\end{tabular}

Regressions (1) and (2) in Table 4 present results from logit regressions that control for observable differences e.g. product types and socio-demographic characteristics of participants ${ }^{26}$. The coefficients confirm that the likelihood of switching from a dirty to a clean product is significantly

\footnotetext{
${ }^{26}$ The sample used in this regression is restricted to observations with 'dirty' baseline choices in all product categories.
} 
lower in the Subsidy treatment than both in the NeutralPriceChange and the Labelling treatments. ${ }^{27}$ This finding not only rejects Hypothesis $3 \mathrm{~b}$, but confirms the exact opposite. The instrument that combines both drivers of switching behaviour performs worse than if each driver is applied separately.

Regression (3) in Table 4 includes an interaction term between the Subsidy dummy and Log of Income. The results indicate that the crowding-out in the Subsidy treatment is mainly due to participants with average and above average income. For them the negative interaction term dominates the positive direct effect (the mean of Log of Income is 3.2). The effect of income on crowding is intuitive since poorer consumers face a tougher trade-off between money and an urge to resist government intervention.

Taken together, the tests of hypotheses $3 \mathrm{a}$ and $3 \mathrm{~b}$ provide evidence of crowding-out of intrinsic motivation. The pre-existing intrinsic motivation activated or re-enforced by information on relative carbon footprints, is not inducing any additional changes. Quite the contrary: the sensitivity to a change in relative prices is reduced if the price change is framed as an explicit intervention in the form of a GHG abatement subsidy. Hence, the combined effect of a price change and information is not only sub-additive (crowding-out) but smaller than each effect individually (over-crowding). While effects similar to over-crowding have been covered in the theoretical literature (Bowles and Hwang, 2008), we are not aware of any other evidence of its existence.

27 While there is no significant difference between switching frequencies in the NeutralPriceChange and the Labelling treatments, the null hypothesis that the coefficients of the Labelling and the Subsidy dummies are the same is rejected at the $1 \%$-level $(p=0.0088)$. 
Table 4: Logit regressions on drivers of switching from dirty to clean products in Labelling, NeutralPriceChange (baseline) and Subsidy treatments. Dependent variable: Switching dummy (1 if participant switches from dirty to clean product), clustered at participant level, 493 independent observations.

(1) (2)

Twenty controls\& Eight controls\& Interaction Term

\begin{tabular}{|c|c|c|c|c|c|c|}
\hline Subsidy & $-0.687^{* *}$ & $(0.011)$ & $-0.759 * * *$ & $(0.003)$ & 1.409 & $(0.205)$ \\
\hline Subsidy x Log of Income & & & & & $-0.669 *$ & $(0.052)$ \\
\hline Labelling & 0.253 & $(0.433)$ & & & & \\
\hline Milk & $-1.864^{* * *}$ & $(0.000)$ & $-1.872^{* * *}$ & $(0.000)$ & $-1.899 * * *$ & $(0.000)$ \\
\hline Meat & $-1.548^{* * *}$ & $(0.000)$ & $-1.572^{* * *}$ & $(0.000)$ & $-1.583^{* * *}$ & $(0.000)$ \\
\hline Butter & $-0.962^{* * *}$ & $(0.004)$ & $-0.979 * * *$ & $(0.004)$ & $-1.050^{* * *}$ & $(0.002)$ \\
\hline \# of children in household & $-0.295^{* *}$ & $(0.034)$ & $-0.225^{* *}$ & $(0.046)$ & $-0.213^{*}$ & $(0.068)$ \\
\hline Male & -0.0603 & $(0.808)$ & & & & \\
\hline Unemployed & -0.713 & $(0.286)$ & & & & \\
\hline Retired & 0.379 & $(0.627)$ & & & & \\
\hline Log of Income & 0.0979 & $(0.589)$ & & & 0.268 & $(0.171)$ \\
\hline Observations & 666 & & 666 & & 666 & \\
\hline Pseudo $R^{2}$ & 0.133 & & 0.126 & & 0.132 & \\
\hline chi2 & 79.08 & & 72.86 & & 75.75 & \\
\hline \multicolumn{7}{|l|}{$p$-values in parentheses } \\
\hline \multicolumn{7}{|c|}{${ }^{*} p<0.10,{ }^{* *} p<0.05,{ }^{* * *} p<0.01$} \\
\hline
\end{tabular}




\section{Result 3}

A subsidy combining a price change and information on relative environmental performance of products via an explicit intervention is less effective in activating intrinsic motivation than either a carbon label or a neutral equivalent price change (crowding out).

This observation would be in line with 'rational' crowding based on signalling of the size of the environmental advantage of clean products by the regulator (Bénabou and Tirole, 2003) assuming that the regulator is better informed about the environmental damages associated with different products and that consumers update their beliefs based on the size of the subsidy. This can explain crowding out under two conditions: A substantial share of participants a) held prior beliefs about the carbon footprints of products and b) perceived the level of the subsidy (but not the actual footprint provided in the Labelling treatment) as a signal that they had overestimated the advantage of clean varieties. As we have argued previously, information on carbon footprints of the products used was not generally available prior to our experiment. Moreover, if the above conditions would be met, we would also expect to see a difference between the Subsidy and the NeutralPriceChange in the number of switches from clean to dirty. The same updating mechanism would induce some participants to switch from clean to dirty as dirty appears no longer as bad as it was when taking the baseline choice in the Subsidy treatment. However, there is no evidence of such an effect. The only product for which there is a significant difference in the clean to dirty switching between the two treatments (at the $10 \%$ level using Fisher's exact test and a test of proportions) is cola but in the opposite direction. Hence, participants do not appear to have arrived at the experiment with an overestimation of the climate benefits of clean options. Vertical signalling as proposed by Bénabou and Tirole (2003) doesnot explain our findings.

One potential problem is that the information provided in the Labelling and Subsidy treatments is not exactly the same. The former presents carbon footprints while the latter only identifies the relative ranking of products. While this could explain sub-additivity, it cannot be the sole reason of over-crowding and the failure of a subsidy to induce switching. Furthermore, there is evidence that 
participants did not pay close attention to the size of the difference in carbon footprints ${ }^{28}$. It therefore seems reasonable to assume that information on relative rankings of products is sufficient to activate intrinsic motivation.

\section{Discussion: who is messing with my groceries?}

It is our hypothesis that the primary distinction between treatments is the exposure of the consumer's private decision-making to government intervention. In the Labelling treatment, consumers were subject to an intervention but it neither changed prices nor the choice set. . Consumers could choose to ignore the information entirely, and so exposure of the grocery-shopping decision-making was entirely voluntary. In the NeutralPriceChange treatment the price-change was involuntary, but it was framed as a market phenomenon, i.e. it was not an intervention imposed by some external (only faceless market forces). Consumers responded in the expected ways.

The Subsidy treatment combined the involuntary nature of a price change with an explicit intervention. Here, the consumer's formerly private decision making realm was being impacted without the consent of the consumer. Although the consumer's welfare was weakly improved by reason of both the increase in its private budget (the subsidy) and the proposed increase in the public good (the public benefits from reduced climate change), the reduction of the private realm of consumer choice was rejected by participants.

It is interesting that consumers might be contesting the division between the private and the public realms of choice. This is another, potentially competing explanation for the phenomenon of crowding out. It could be that intrinsic motivation to provide public goods is complemented by an inbuilt belief that there should be a separation between the private and the public realms of choice. Citizens might be defending their boundaries around the private realm of behaviour as much as they are the public realm.

\footnotetext{
28 The Labelling treatment was run in three different versions which differed in the carbon footprints provided (only the version with the true footprints is reported in this paper). There was no systematic effect of the scale of potential GHG reductions on participants switching behaviour. Furthermore, all results presented on the Labelling treatment would hold if all three versions of it would have been included.
} 


\section{Conclusions}

Our findings provide the first direct evidence of motivation crowding in real consumer purchasing decisions. We find an explicit price intervention crowds-out (and even 'over-crowds') intrinsic motivation.

To summarize the key results, information provision through labelling is able to induce shoppers to switch to more climate friendly product varieties by activating or re-enforcing their preexisting intrinsic motivation to contribute to climate change mitigation. It is interesting to note that approximately twenty per cent of consumers require only information to give effect to socially beneficial behaviour. ${ }^{29}$ However, combining information on the relative environmental performance of products with a monetary reward for switching is less effective than information alone. Moreover, using a subsidy as an explicit regulatory intervention performs worse than an equivalent but neutrally framed price change. This result indicates that the framing of otherwise equivalent changes in the incentive structure matters for intrinsic motivation and is in line with findings by Goeschl and Perino (2012) who observe crowding-out of intrinsic motivation by an environmental tax compared to a neutrally framed price change. Hence, the negative effects of a price intervention seem to be broadly similar for taxes and subsidies.

From a policy perspective we are investigating the ability of various instruments to complement intrinsic motivation in public goods provision within the context of private consumption decisions. In other words, what works to activate consumer's public-spiritedness within the realm of private decision-making?

Our findings represents clear evidence in support of the standard "crowding out" effect, i.e. the effect that adding the subsidy to the information does not improve performance of the instrument. More practically, it means that a governmental intervention that is highly visible to consumers might

\footnotetext{
${ }^{29}$ This is in line with evidence on the effect of labelling in other contexts (Bjørner et al., 2004; Noussair et al., 2004).
} 
be less effective than a more 'hidden' tax or subsidy. ${ }^{30}$ More interestingly, it might also mean that there is a more fundamental cause of some of these observed "crowding" effects. The resistance of consumers to forced interventions, even those representing unambiguous increases in welfare such as a subsidy, is indicative of a resistance of consumers to altering the line between private and public decision making - in either direction. It could be that consumers are as interested in keeping governmental interventions outside of certain realms of normally private decision-making, as they are in keeping market-based interventions outside of certain realms of normally social decision-making.

Taken together, the results from this experiment suggest that a government working in an area of consumer choice imbued with both public and private good characteristics should proceed carefully in its selection of instruments. Not all instruments have the same effect when operating around the boundaries between private and public goods, simply because citizens (and consumers) might resist the alteration of that boundary.

A number of caveats are in order. Firstly, by design the experiment can only capture short term effects. Switching patterns might be different in the long-run as previous studies have found diverging results on long-term persistence of crowding-out (Meier, 2007; Goeschl and Perino, 2012). Secondly, the credibility of the framings can be questioned on the grounds that participants were fully aware that they were participating in an experiment and that any subsidy or price change would not be permanent, and that any government involvement is hypothetical. However, if participants would indeed have found the framing unconvincing, we should not have found any significantly different effects between the Subsidy and the NeutralPriceChange treatments. The fact that we did, indicates that the setup did work as intended.

\section{References}

Andreoni, J. 1988. "Privately provided public goods in a large economy: The limits of altruism" Journal of Public Economics 35:57-73.

\footnotetext{
${ }^{30}$ This complements findings by Kallbekken et al. (2011) who establish an aversion against interventions labelled as a 'tax' compared to an equivalent with a different name. These findings do not contradict results by Chetty et al. (2009) as they compare changes in taxes already included in the product's price with taxes that are added at the check-out.
} 
Andreoni, J. 1989. "Giving with impure altruism: applications to charity and Ricardian equivalence", Journal of Political Economy 97(6):1447-1458.

Arce, D. G. 2007. “Is agency theory self-activating?” Economic Inquiry 45(4):708-720.

Ariely, D., A. Bracha, and S. Meier. 2009. “Doing Good or Doing Well? Image Motivation and Monetary Incentives in Behaving Prosocially." American Economic Review 99(1):544-55.

Bem, D.J. 1967. "Self-perception: An alternative interpretation of cognitive dissonance phenomena" Psychological Review 74(3):183-200.

Bénabou, R., and J. Tirole. 2003. "Intrinsic and extrinsic motivation." Review of Economic Studies 70:489-520.

Bénabou, R., and J. Tirole. 2006. "Incentives and prosocial behaviour." American Economic Review 96(5):1652-1678.

Bhapkar, V.P. 1966. "A note on the equivalence of two test criteria for hypotheses in categorical data" Journal of the American Statistical Association 61(313):228-235.

Bjørner, T.B., L.G. Hansen and C.S. Russell. 2004. “Environmental labelling and consumers' choice - an empirical analysis of the effect of the Nordic Swan" Journal of Environmental Economics and Management 47(3):411-434.

Bowles, S. 2008. "Policies designed for self-interested citizens may undermine "the moral sentiments": evidence from economic experiments." Science 320:1605-1609.

Bowles, S. and S.-H. Hwang. 2008. "Social Preferences and Public Economics: Mechanism design when social preferences depend on incentives" Journal of Public Economics 92(8-9):1811-1820.

Carlsson-Kanyama, A. and A. D. González. 2009. "Potential contribution of food consumption patterns to climate change", American Journal of Clinical Nutrition 89(5): 1704-1709.

Charness, G. and U. Gneezy. 2009. “Incentives to exercise.” Econometrica 77(3):909-931.

Chetty, R., A. Looney and K. Kroft. 2009. "Salience and Taxation: Theory and Evidence" American Economic Review 99(4):1145-1177.

Corgnet, B. 2012. "Peer evaluations and team performance: When friends do worse than strangers" Economic Inquiry 50(1):171-181 
Deci, E. and R.M. Ryan. 1985. "Intrinsic Motivation and Self-Determination in Human Behaviour" Plenum Press, New York.

DEFRA. 2002. "Valuing the Social Cost of Carbon Emissions: DEFRA Guidance". London: DEFRA. Available online at http://www.hm-treasury.gov.uk/d/SCC.pdf

Eckel, C. C. and P. J. Grossman. 2003. "Rebate versus matching: does how we subsidize charitable contributions matter?" Journal of Public Economics 87(3-4):681-701

Ellingsen, T., and M. Johannesson. 2008. "Pride and prejudice: The human side of incentive theory." American Economic Review 98(3):990-1008.

Eshel, G. and P.A. Martin. 2006. “Diet, Energy, and Global Warming” Earth Interactions, 10: 1-17.

Falk, A. and M. Kosfeld: 2006. "The hidden costs of control." American Economic Review 96(5):16111630.

Fehr, E. and A. Falk. 2002. "Psychological foundations of incentives" European Economic Review 46:687-724.

Fehr, E. and K. M. Schmidt. 2000. "Fairness, incentives, and contractual choices" European Economic Review 44:1057-1068.

Frey, B.S. 1993. "Does monitoring increase work effort? The rivalry with trust and loyalty" Economic Inquiry 31:663-670.

Frey, B. S. and M. Benz. 2005. “Can private learn from public governance?" Economic Journal 115: F377-F396.

Frey, B. S. and F. Oberholzer-Gee. 1997. "The cost of price incentives: An empirical analysis of motivational crowding-out." American Economic Review 87(4):746-755.

Frey, B. S. 1997. Not Just for the Money: An Economic Theory of Personal Motivation. Cheltenham, UK, Edward Elgar Publishing.

Frey, B. S. and R. Jegen. 2001. "Motivation Crowding Theory" Journal of Economic Surveys 15(5):589611.

Frohlich, N. and J. Oppenheimer. 2003. "Optimal policies and socially oriented behavior: Some problematic effects of an incentive compatible device." Public Choice 117:273-293. 
Gneezy, U., and A. Rustichini. 2000a. “A fine is a price.” Journal of Legal Studies 29(1):1-17.

Gneezy, U., and A. Rustichini, 2000b. "Pay enough or don't pay at all." Quarterly Journal of Economics 115(2):791-810.

Goeschl, T., and G. Perino. 2012. "Instrument Choice and Motivation: Evidence from a Climate Change Experiment." Environmental and Resource Economics 52(2):195-212.

Harrison, G. W. and J. A. List. 2004. "Field experiments" Journal of Economic Literature 42:1009-1055.

Heyes, A. and S. Kapur. 2011. "Regulating altruistic agents" Canadian Journal of Economics 44(1):227246.

Heyman, J. and D. Ariely. 2004. "Effort for Payment: A Tale of Two Markets" Psychological Science 15(11):787-793.

Kahneman, D., J. L. Knetsch, and R. Thaler. 1986. "Fairness as a Constraint on Profit Seeking: Entitlements in the Market." American Economic Review 76(4):728-741.

Kallbekken, S., S. Kroll, and T.L. Cherry. 2011. "Do you not like Pigou, or do you not understand him? Tax aversion and revenue recycling in lab" Journal of Environmental Economics and Management 62(1):53-64.

Landry, C.E., A. Lange, J.A. List, M.K. Price and N.G. Rupp. 2011. "Is there a 'hidden cost of control' in naturally occurring markets? Evidence from a natural field experiment" NBER Working Paper 17472.

Meier, S. 2007. "Do subsidies increase charitable giving in the long run? Matching donations in a field experiment" Journal of the European Economic Association 5(6):1203-1222.

Meier, S. and A. Stutzer. 2008. „Is Volunteering Rewarding in Itself?” Economica 75(297):39-59.

Mellström, C. and M. Johannesson. 2008. "Crowding Out in Blood Donation: Was Titmuss Right?" Journal of the European Economic Association 6(4):845-863.

Mintel. 2009. "Many consumers yet to click with online grocery shopping", Press release, http://www.mintel.com/press-centre/press-releases/400/many-consumers-yet-to-click-withonline-grocery-shopping (accessed 6th March 2011).

Nafziger, J. 2011. “Motivational Job Assignments” Economica 78(312):676-696. 
Noussair, C., S. Robin and B. Ruffieux 2004. "Do consumers really refuse to buy genetically modified food?" Economic Journal 114:102-120.

Pearce, D. 2003. "The Social Cost of Carbon and its Policy Implications" Oxford Review of Economic Policy 19(3):362-384.

Schnedler, W. and R. Vadovic. (2011) "Legitimacy of control” Journal of Economics and Management Strategy 20(4):985-1009.

Sliwka, D. 2007. "Trust as a signal of a social norm and the hidden costs of incentive schemes." American Economic Review 97(3):999-1012.

UK Office for National Statistics. 2005. Socio-economic Classification - User Manual. Basingstoke, UK, Palgrave Macmillan.

Weber, C. L. Matthews, H. S. 2008. "Food-Miles and the Relative Climate Impacts of Food Choices in the United States" Environmental Science and Technology , 42 (10): 3508-3513 


\section{Appendix A}

\section{Table A.1: Variable Descriptions}

\section{Variable \\ Description}

\section{Treatment dummies}

Labelling

Dummy: 1 if participant was subject to Labelling treatment, 0 otherwise

Subsidy

Dummy: 1 if participant was subject to Subsidy treatment, 0 otherwise

NeutralPriceChange

Dummy: 1 if participant was subject to NeutralPriceChange treatment, 0

otherwise

\section{Product dummies}

Milk

Dummy: 1 for milk, 0 otherwise

Meat

Dummy: 1 for meat, 0 otherwise

Butter

Dummy: 1 for butter/margarine, 0 otherwise

\section{Location dummies}

L.NewBarnet Dummy: 1 if observation is from store in New Barnet, 0 otherwise.

L.Edgware Dummy: 1 if observation is from store in Edgware, 0 otherwise.

L.Chiswick Dummy: 1 if observation is from store in Chsiwick, 0 otherwise.

L.Merton Dummy: 1 if observation is from store in Merton, 0 otherwise.

L.Walthamstow Dummy: 1 if observation is from store in Walthamstow, 0 otherwise.

\section{Socio-demographic variables}

Envinfo

Dummy: 1 if participant opts to read the environmental information sketching the problem of climate change and the meaning of a carbon label, 0 otherwise.

Nutrinfo

Dummy: 1 if participant opts to read the nutritional information 
sketching the health impact of energy, proteins, carbohydrates, fat and salt referred to on food labels, 0 otherwise.

\# of children in Number of children (below 12 years old) in the household

household

\# of persons in Number of persons living in a household

household

Male

Dummy: 1 if participant is male, 0 otherwise.

Age

Age of participant

Student

Dummy: 1 if participant is a student, 0 otherwise.

Ncsec

Socio-economic class, based on participants' occupation in accordance with UK Office for National Statistics 2005 guidelines.

Unemployed

Dummy: 1 if participant is unemployed, 0 otherwise.

Retired

Dummy: 1 if participant is retired, 0 otherwise.

Edu1

Dummy: 1 if participant does not have any university-level education, 0 otherwise.

Log of Income $\quad$ Log of household income (in thousand GBP) 
Table A.2: Choices in Labelling Treatment (Milk)

\begin{tabular}{|c|c|c|c|c|c|}
\hline & & \multicolumn{3}{|c|}{ Choice 2} & \\
\hline & & Whole & Semi-skimmed & Skimmed & \\
\hline \multirow{4}{*}{ 光 } & Whole & 15 & 2 & 2 & 19 \\
\hline & Semi-skimmed & 0 & 29 & 2 & 31 \\
\hline & Skimmed & 0 & 0 & 7 & 7 \\
\hline & & 15 & 31 & 11 & 57 \\
\hline
\end{tabular}

Table A.3: Choices in Labelling Treatment (Cola, Butter/Margarine and Meat)

\begin{tabular}{|l|l|l|l|l|}
\hline & & \multicolumn{2}{|l|}{ Choice 2 } & \\
\hline & & Dirty & Clean & \\
\hline \multirow{2}{*}{} & Dirty & 27 & 16 & 43 \\
\cline { 2 - 5 } & Clean & 3 & 27 & 30 \\
\hline & & 30 & 43 & 73 \\
\hline
\end{tabular}

Table A.4: Choices in NeutralPriceChange Treatment (Milk)

\begin{tabular}{|c|c|c|c|c|c|}
\hline & & \multicolumn{3}{|c|}{ Choice 2} & \\
\hline & & Whole & Semi-skimmed & Skimmed & \\
\hline \multirow{4}{*}{ 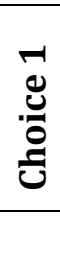 } & Whole & 45 & 11 & 1 & 57 \\
\hline & Semi-skimmed & 3 & 88 & 9 & 100 \\
\hline & Skimmed & 2 & 2 & 14 & 18 \\
\hline & & 50 & 101 & 24 & 175 \\
\hline
\end{tabular}

Table A.5: Choices in NeutralPriceChange Treatment (Cola, Butter/Margarine and Meat)

\begin{tabular}{|c|c|c|c|c|}
\hline & & \multicolumn{2}{|c|}{ Choice 2} & \\
\hline & & Dirty & Clean & \\
\hline \multirow{3}{*}{ } & Dirty & 105 & 45 & 150 \\
\hline & Clean & 19 & 64 & 83 \\
\hline & & 124 & 109 & 233 \\
\hline
\end{tabular}


Table A.6: Choices in Subsidy Treatment (Milk)

\begin{tabular}{|c|c|c|c|c|c|}
\hline & & \multicolumn{3}{|c|}{ Choice 2} & \\
\hline & & Whole & Semi-skimmed & Skimmed & \\
\hline \multirow{4}{*}{ } & Whole & 54 & 5 & 0 & 59 \\
\hline & Semi-skimmed & 3 & 72 & 7 & 82 \\
\hline & Skimmed & 1 & 2 & 9 & 12 \\
\hline & & 58 & 79 & 16 & 153 \\
\hline
\end{tabular}

Table A.7: Choices in Subsidy Treatment (Cola, Butter/Margarine and Meat)

\begin{tabular}{|c|c|c|c|c|}
\hline & & \multicolumn{2}{|c|}{ Choice 2} & \\
\hline & & Dirty & Clean & \\
\hline \multirow{3}{*}{ 苞 } & Dirty & 102 & 23 & 125 \\
\hline & Clean & 18 & 73 & 91 \\
\hline & & 120 & 96 & 216 \\
\hline
\end{tabular}


Table A.8: Summary Statistics

$\begin{array}{lll}\text { Variable } & \text { Mean } & \text { Std. Dev. } \\ \text { Labelling } & 0.14 & 0.35 \\ \text { Subsidy } & 0.41 & 0.49 \\ \text { NeutralPriceChange } & 0.45 & 0.50 \\ \text { Milk } & 0.42 & 0.49 \\ \text { Meat } & 0.18 & 0.38 \\ \text { Butter } & 0.23 & 0.42 \\ \text { L.NewBarnet } & 0.06 & 0.23 \\ \text { L.Edgware } & 0.17 & 0.38 \\ \text { L.Chiswick } & 0.19 & 0.39 \\ \text { L.Merton } & 0.30 & 0.46 \\ \text { L.Walthamstow } & 0.11 & 0.31 \\ \text { Envinfo } & 0.37 & 0.48 \\ \text { Nutrinfo } & 0.58 & 0.49 \\ \text { \# of children in household } & 0.64 & 1.02 \\ \text { \# of persons in household } & 2.94 & 1.65 \\ \text { Male } & 0.35 & 0.48 \\ \text { Age } & 37.4 & 12.13 \\ \text { Student } & 0.08 & 0.27 \\ \text { Ncsec } & 8.53 & 4.22 \\ \text { Unemployed } & 0.04 & 0.21 \\ \text { Retired } & 0.04 & 0.20 \\ \text { Edu1 } & 0.40 & 0.49 \\ \text { Income (in '000 GBP) } & 30.45 & 18.14\end{array}$

